Special Issue of the 7th International Advances in Applied Physics and Materials Science (APMAS 2017)

\title{
Cyclic Oxidation Behavior of c-BN and h-BN at Elevated Temperatures
}

\author{
İ.ÖZKAN ${ }^{a, *}$, E. DOKUMACI ${ }^{b}$ AND A.B. ÖNAY ${ }^{b}$ \\ ${ }^{a}$ Dokuz Eylül University, Torbali Vocational School, Industrial Glass and Ceramics Department, 35860 Izmir, Turkey \\ ${ }^{b}$ Dokuz Eylül University, Faculty of Engineering, Metallurgical and Materials Engineering Department, \\ 35390 Izmir, Turkey
}

\begin{abstract}
The aim of this study is to determine the cyclic oxidation behavior of cubic boron nitride (c-BN) and hexagonal boron nitride $(\mathrm{h}-\mathrm{BN})$ in air atmosphere at elevated temperatures. For this purpose, as-received powders of both compounds were first characterized by XRD and SEM. c-BN and h-BN powders were shaped by cold pressing for oxidation studies. Tests were performed in air atmosphere at $800^{\circ} \mathrm{C}$ and $1000^{\circ} \mathrm{C}$ for $5,10,15$ and 20 hours. After each oxidation test, the mass changes were measured. XRD, SEM and EDS analyses were conducted on the oxidized samples and the results were discussed.
\end{abstract}

DOI: 10.12693/APhysPolA.134.61

PACS/topics: cyclic oxidation, c-BN, h-BN

\section{Introduction}

Boron nitride $(\mathrm{BN})$ is an inorganic material with a wide application area in industry due to the similarity of its crystal structures and phase changes to those of carbon, high thermal shock resistance, high thermal conductivity, high dielectric constant, chemical stability, and lubricating properties. It is a chemical compound with chemical formula of BN, consisting of equal numbers of boron and nitrogen atoms [1].

Boron nitride is known to exist in several modifications and these are of considerable interest, since their structural forms and certain physical characteristics are similar to analogous properties of carbon modifications. The use of boron nitride in various fields of technology is constantly growing [2]. Although $\mathrm{BN}$ is a compound, its structure is often compared to that of carbon. There are three forms of $\mathrm{BN}$ : $\alpha-\mathrm{BN}$ or h-BN which has a layered hexagonal structure, similar to graphite; $\beta$-BN or $\mathrm{c}-\mathrm{BN}$, a diamond-like material, formed under high pressure with a cubic zinc blende structure; and $\gamma$-BN, which has a wurtzite structure [3].

In particular, studies on corrosion resistance of boron nitride in oxidizing media at high temperatures are especially important for determining specific fields of application and temperature ranges of the corresponding processes [2]. In literature, there are studies examining the oxidation properties of dense-sintered boron nitride samples $[1,2,4-6]$. In addition to these studies, oxidation behavior of cold pressed c-BN and h-BN needs to be considered. This paper describes the cyclic oxidation behavior of cold pressed c-BN and h-BN pellets in air at elevated temperatures.

*corresponding author; e-mail: ilker.ozkan@deu.edu.tr

\section{Materials and equipment}

In this study commercial c-BN and h-BN powders obtained from Element 6 company (South Africa) were used. According to the information received from the suppliers, c-BN and h-BN powder grains have dimensions of $2-4 \mu \mathrm{m}$. Powders were compacted as pellets for proper measurement. Pellets were formed by using a mould with $20 \mathrm{~mm}$ diameter and cold pressed under a 150 bar forming pressure. To improve the plasticity and mechanical strength of the pellets, carboxymethyl cellulose (CMC) was added as an aqueous solution (4\% by weight). It was observed that after drying at $110^{\circ} \mathrm{C}$, pellets became harder and therefore were suitable to use in the oxidation tests. To be able to measure properly the weight changes of the pellets after the oxidation tests, it was necessary to drill a hole through the pellets. Pellet samples were then suspended inside a quartz crucible.

Oxidation tests were conducted in a box furnace at temperatures between 800 and $1200{ }^{\circ} \mathrm{C}$ for a total of $20 \mathrm{~h}$ in 4 cycles, each lasting $5 \mathrm{~h}$. Before and after each oxidation test, sample mass changes and dimensions of the samples were measured and mass changetime graphics were drawn. The surface morphologies and microstructures of the oxidized pellets were investigated using JEOL-JSM 6060 scanning electron microscope (SEM). An X-ray diffractometer (Rigaku D/Max$2200 / \mathrm{PC}$ ) with a $\mathrm{Cu} \mathrm{K} \mathrm{K}_{\alpha}$ tube was used to determine the oxidation products formed on the pellet samples.

\section{Results and discussion}

\subsection{Characterization of the powder samples}

Figure 1 shows the results XRD analysis of as received $\mathrm{h}-\mathrm{BN}$ and c-BN powder. According to the XRD data base the h-BN powder sample shows similarity with the $\mathrm{BN}$ material that has a catalogue number of 034-0421 and the c-BN powder sample shows similarity with the $\mathrm{BN}$ material that has a catalogue number of 035-1365. 

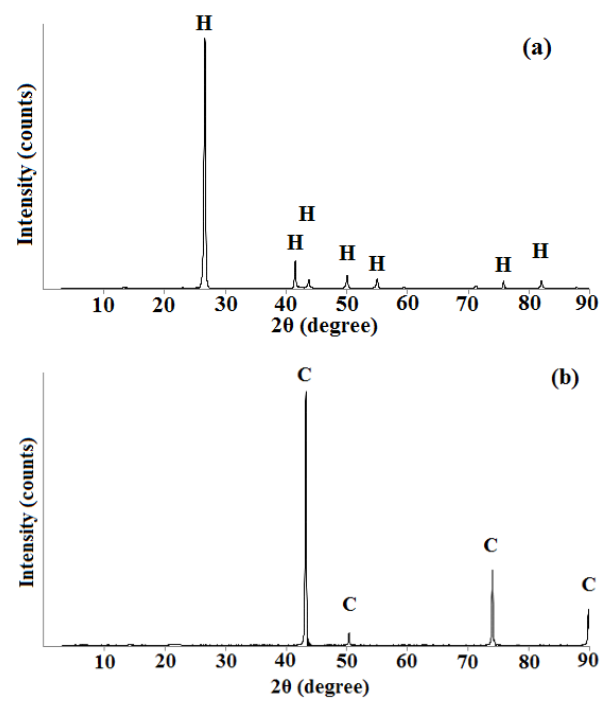

Fig. 1. XRD patterns of as-received (a) h-BN and (b) c-BN powder. (H: h-BN, C: c-BN).

Figure 2 shows SEM images of the as received (a) h-BN and (b) c-BN powder. In Fig. 2a, powder crystals with lamellar geometric shapes and dimensions in a few micrometers range are observed. EDS analysis of the white square area in Fig. 2a has shown that the selected area contained $80.078 \%$ of $\mathrm{B}$ and $19.922 \%$ of N. Figure $2 \mathrm{~b}$ shows SEM images of the c-BN powder. Here, powder crystals are observed to have cubic shapes and dimensions of a few micrometers. EDS analysis of the white square area in Fig. $2 \mathrm{~b}$ has shown that the composition of the area was $83.176 \%$ of $\mathrm{B}$ and $14.492 \%$ of $\mathrm{N}$.
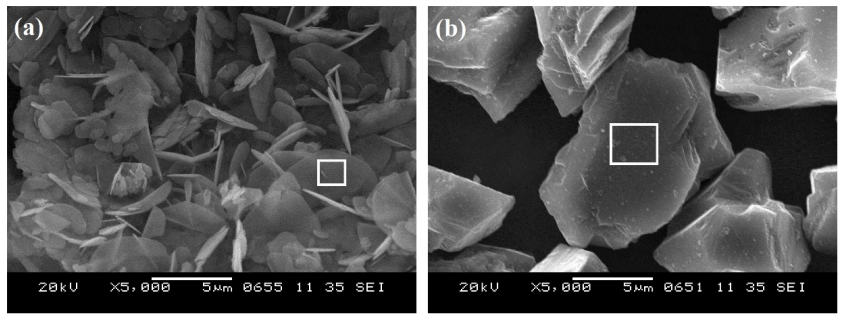

Fig. 2. SEM images of as-received (a) h-BN and (b) c-BN powder.

\subsection{Oxidation test results}

Kinetics of the oxidation behavior can be evaluated by considering the weight change measurements of the tablet samples as well as the corrosion products. Because characteristics of corrosion products have a significant impact on the measured weight changes and depend on the temperature and the duration of the experiments.

For example, if the oxidation products are only in the solid state and did not spall (fall off) from the sample surfaces, the oxidized samples are supposed to have a net increase in their weight. However, if the corrosion products are only in gas state, there will be a decrease in the weight of the oxidized samples. During oxidation, the formation of the liquid phase will cause weight gain or weight loss, depending on the duration and temperature of the tests.

Corrosion products in different states can form on the same sample simultaneously. In all cases, the weight change per unit surface area $\Delta m / A$ is expected to change with the features of the corrosion products and with the experimental conditions (experiment duration $t$ and temperature).

In Fig. 3, $\Delta m / A$ values for h-BN and c-BN are shown as functions of time and temperature. These graphs show that pellet samples have gained weight during oxidation at all temperatures, with the exception of c-BN pellet, oxidized at $800^{\circ} \mathrm{C}$. In Fig. 3 it is also observed that weight changes of the borides have increased with temperature. At $1000^{\circ} \mathrm{C}$, both compounds have shown a rapid weight gain for the 5-hour tests. But later, the rate of weight gain has decreased. At $800^{\circ} \mathrm{C}$ a loss of weight was observed for c-BN.

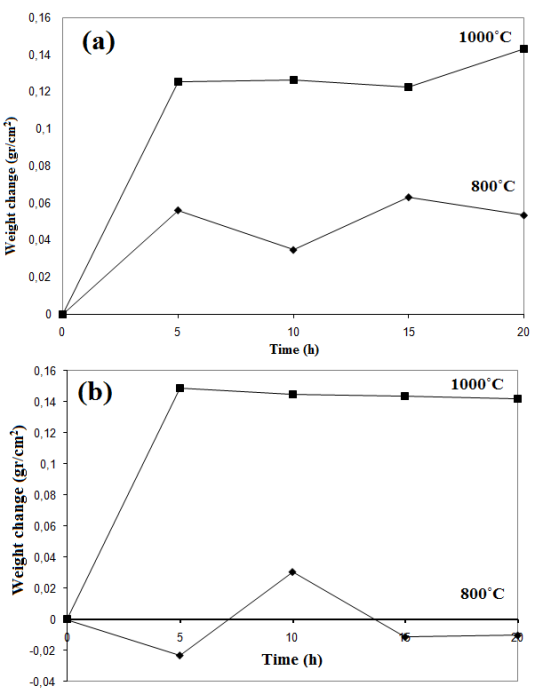

Fig. 3. Relative weight changes of the (a) h-BN, (b) c-BN pellets oxidized at $800{ }^{\circ} \mathrm{C}$ and $1000^{\circ} \mathrm{C}$.

From these results it is possible to suggest a mechanistic model stating that $\mathrm{BN}$ samples lost weight due to the release of nitrogen gas while gaining weight due to the formation of boron oxide. XRD analyses of the oxidized h-BN and c-BN pellets have shown that besides boron nitride phases, $\mathrm{B}_{2} \mathrm{O}_{3}$ phase has formed during the oxidation tests conducted in air at the indicated temperatures (Fig. 4).

Thermodynamic stability of the products resulting from chemical reactions of boron nitride with oxygen can be determined by considering the standard Gibbs free energy changes $\Delta G^{0}$ of the oxidation reactions. Table I shows the chemical reaction and $\Delta G^{0}$ values of the reaction calculated using data from the literature. $\Delta G^{0}$ val- 

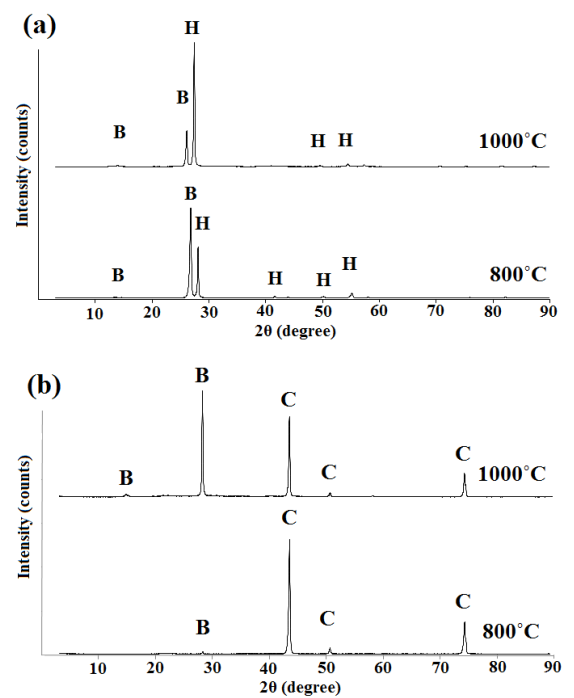

Fig. 4. XRD patterns of the (a) h-BN and (b) c-BN pellets oxidized at different temperatures $(\mathrm{H}$ : h-BN, B: $\left.\mathrm{B}_{2} \mathrm{O}_{3}, \mathrm{C}: \mathrm{c}-\mathrm{BN}\right)$.

ues given in Table I indicate that the oxidation reactions can take place as written at the indicated temperatures and that $\mathrm{B}_{2} \mathrm{O}_{3}(\mathrm{l})$ and $\mathrm{N}_{2}(\mathrm{~g})$ are thermodynamically stable as oxidation/corrosion products.

TABLE I

Oxidation reaction and standard Gibbs free energy changes $\Delta G^{0}(\mathrm{~kJ})[7]$.

\begin{tabular}{c|c|c|c}
\hline \hline Oxidation reaction & $800^{\circ} \mathrm{C}$ & $1000^{\circ} \mathrm{C}$ & $1200^{\circ} \mathrm{C}$ \\
\hline $2 \mathrm{BN}(\mathrm{s})+\frac{3}{2} \mathrm{O}_{2}(\mathrm{~g}) \Rightarrow \mathrm{B}_{2} \mathrm{O}_{3}(\mathrm{l})+\mathrm{N}_{2}(\mathrm{~g})$ & -1191.8 & -1184.7 & -1177.9
\end{tabular}

In addition, $\mathrm{NO}_{2}(\mathrm{~g})$ may form as a product. However, many different rates and rate laws have been reported and there is no agreement on the fundamental mechanism of oxidation. These varying results suggest that oxidation behavior is dependent on such issues as porosity, impurities, and crystalline form [3].

Podobeda et al. have studied the oxidation of $\mathrm{BN}$ powders. They observe two stages of chemical reaction at heating these powders. The first, occurring at $40-400^{\circ} \mathrm{C}$, involves the release of water from the $\mathrm{BN}$ structure. This involves both desorption of water and decomposition of boric acid impurities in the BN. At higher temperatures, Podobeda et al. observe measurable oxidation. The onset of measurable oxidation was generally at about $800^{\circ} \mathrm{C}$ and had tended to decrease with higher oxygen impurity levels within the $\mathrm{BN}[2,8]$.

Lavrenko and Alexeev have reported results for the high temperature oxidation of boron nitride. At temperatures between $600-800^{\circ} \mathrm{C}$, no sample weight change was observed by the authors. Oxidation of the cubic boron nitride was observed to start only at $900^{\circ} \mathrm{C}$ [1].

Figure 5 shows the microstructures of the samples after oxidation. It is observed that different microstructures were formed at different experimental temperatures. The
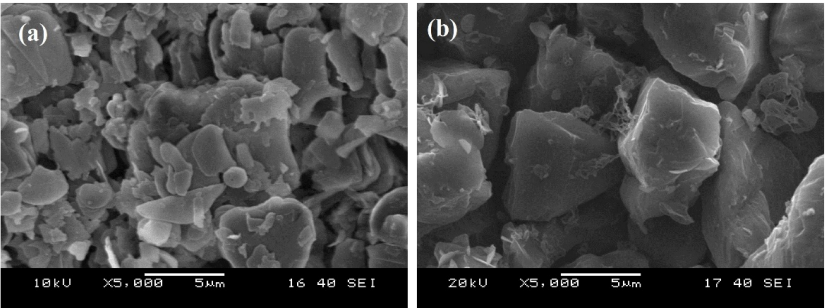

Fig. 5. SEM images of (a) h-BN and (b) c-BN pellets oxidized at $1000^{\circ} \mathrm{C}$ for $10 \mathrm{~h}$.

consolidation of the grains (Fig. 5a and b) and formation of the network-like structure (Fig. 5b) between the grains are seen clearly.

\section{Conclusions}

In this study, cyclic oxidation behaviors of c-BN and h-BN were investigated. The following conclusions can be drawn from the obtained results.

$\mathrm{B}_{2} \mathrm{O}_{3}$ was found to be the main oxidation product. Thermodynamically formation of $\mathrm{N}_{2}(\mathrm{~g})$ is possible. It was observed that cyclic oxidation behavior of the samples depended on temperature and time. At $800^{\circ} \mathrm{C}$ h-BN samples have shown weight gain while c-BN samples have shown weight loss. At $1000^{\circ} \mathrm{C}$ significant weight gains were observed for both of the samples. Formation and volatilization of $\mathrm{B}_{2} \mathrm{O}_{3}$ had a significant effect on the oxidation behavior of the samples.

\section{Acknowledgments}

This study is based on the Project No: 105M362 supported by TÜBİTAK Support Programs for Scientific and Technological Projects.

\section{References}

[1] V.A. Lavrenko, A.F. Alexeev, Ceram. Int. 12, 25 (1986).

[2] N. Jacobson, S. Farmer, A. Moore, H. Sayir, J. Am. Ceram. Soc. 82(2), 393 (1999).

[3] N. Dökmetas, M.Sc. Thesis Investigation of Boron Nitride Coatings, Atılım University, The Graduate School of Natural and Applied Sciences 2014.

[4] N.S. Jacobson, G.N. Morscher, D.R. Bryant, R.E. Tressler, J. Am. Ceram. Soc. $\mathbf{8 2}(6), 1473$ (1999).

[5] C.G. Cofer, J. Economy, Carbon 33(4), 389 (1995).

[6] T.B. Do, J.W. Halloran, J. Am. Ceram. Soc. 91(8), 2730 (2008)

[7] E.T. Turkdoğan, Physical Chemistry of High Temperature Technology, Academic Press Inc, San Diego 1980.

[8] L.T. Podobeda, A.K. Tsapuk, A.D. Buravov, Sov. Powder Metall. 15(9), 696 (1976). 